\title{
Which is the most affected muscle in lumbar back pain - multifidus or erector spinae?
}

\author{
Pırıl Erbay Öztürk ${ }^{A, B, D, E, F}$, Nilüfer Aylanç, $\mathrm{A}, \mathrm{B}, \mathrm{C}, \mathrm{D}, \mathrm{E}, \mathrm{F}$ \\ Department of Radiology, Faculty of Medicine, Çanakkale Onsekiz Mart University, Çanakkale, Turkey
}

\section{Abstract}

Purpose: The purpose of this study is to evaluate the relationship between lumbar back pain, lumbar disc herniation, and erector spinae and multifidus muscle lipomatous degeneration.

Material and methods: After receiving approval from the clinical studies Ethics Committee, magnetic resonance imaging (MRI) studies of patients who had physical examination in orthopaedic, neurology, neurosurgery, physical medicine and rehabilitation clinics were evaluated. Their pre-diagnoses were 'herniated nucleus pulposus' or 'lumbar disc herniation' or 'back pain' and their age range was between 18 and 64 years. Patients who had vertebral fracture, spondylitis-spondylodiscitis, tumours, structural anomalies such as spondylolisthesis, scoliosis and vertebral segmentation anomalies and previous surgery in the lumbar area were excluded. There were 205 patients in the case group who had lumbar disc herniation between L1-S1 level and there were 187 patients in the control group who had no lumbar disc herniation. In the study, patient age, sex, herniation level and erector spinae and multifidus muscle lipomatous degeneration were compared. Muscle lipomatous degeneration were evaluated with a visual scale.

Results: There were 105 men and 100 women in the case group and 88 men and 99 women in the control group. In the case group, lumbar disc herniation was detected mostly at L4-5 and L5-S1 levels. There was no significant difference between case and control groups with regard to erector spinae and multifidus muscle lipomatous degeneration. In the case group, lipomatous degeneration of the erector spinae was higher compared to that of the multifidus muscle.

Conclusions: Patients with low back pain may have fatty degeneration in erector spina and multifidus muscles with or without $\mathrm{LDH}$, but $\mathrm{LDH}$ accelerates this process rather than being a result of it. In patients with LDH, fatty degeneration in the erector spina is more pronounced than in multifidus, and the erector spina is more affected by the LDH process.

Key words: back pain, lumbar disc herniation, multifidus, erector spinae.

\section{Introduction}

It is known that $80 \%$ of adults experience low back pain (LBP) at least once during their lifetime, which is linked to different causes. Due to frequent incidence and causing morbidity in the short and long term, it is a health problem with high socioeconomic costs to society $[1,2]$. If we examine the causes of LBP, a broad framework, from traumatic events to working conditions, of demographic characteristics to congenital malformations, is observed.
Lumbar disk herniation (LDH) is one of the processes causing a significant degree of low back pain [3].

LBP is defined as "disc material, localised or focally, found outside the boundaries of the intervertebral disc interval" [4]. It occurs with a variety of degrees and may or may not cause spinal channel and neural foramen narrowing, leading to a variety of degrees of nerve compression. These cases have symptoms from pain to sensory defects or neurological deficits.

\footnotetext{
Correspondence address:

Nilüfer Aylanç, MD, Department of Radiology, School of Medicine, Çanakkale 18 Mart University, 17100 Çanakkale, Türkiye, mobile tel.: +90 5058569606,

tel.: +9028621800 18, fax: +9028621837 38, e-mail: niluferaylanc@gmail.com
}

Authors' contribution:

A Study design · B Data collection · C Statistical analysis · D Data interpretation · E Manuscript preparation · F Literature search · G Funds collection 


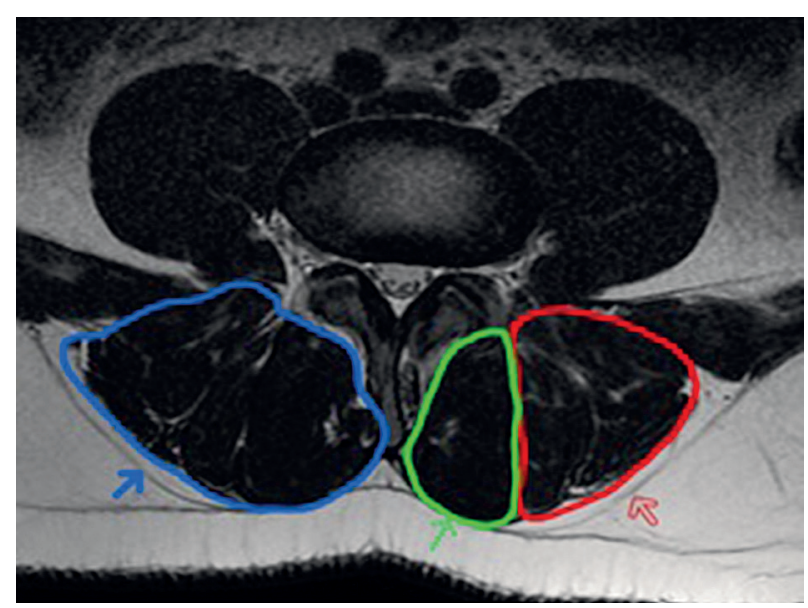

Figure 1. Axial T2-weighted magnetic resonance image of posterior paravertebral muscles showing the paravertebral muscle group (blue arrow), multifidus muscle (green arrow), and erector spinae muscle (red arrow)

Paravertebral muscles, playing a large role in ensuring the balance of the vertebral column (Figure 1), are the basic supporter of the vertebral column and the most important factor ensuring stabilisation of the vertebral column in situations such as load carrying [5]. Due to increased immobilisation linked to age or as a result of denervation forming with a variety of causes, these muscles may undergo fatty degeneration. As a result, the status of the paravertebral muscles is important for the assessment and management of LBP and pathologies causing LBP.

The aim of our study is to evaluate the relationship between erector spinae and multifidus, which are posterior paravertebral muscles, with lumbar disc hernias and fatty degeneration.

\section{Material and methods}

\section{Selection of case and control groups}

Permission was granted by the clinical research Ethics Committee of Çanakkale Onsekiz Mart University before the study. For this study we scanned patients with lumbar magnetic resonance imaging (MRI) between April 2015 to April 2016. Patients aged 18-64 years, from neurosurgery, neurology, orthopaedic, and physical therapy and rehabilitation clinics, with initial diagnosis of LBP, radicular pain, or $\mathrm{LDH}$ were included in this study. Patients with vertebral fracture, spondylitis-spondylodiscitis, tumour, structural anomalies (spondylolisthesis, scoliosis, vertebra segmentation anomalies, etc.), and patients with previous surgery in the lumbar region were excluded. Also, patients with intervertebral disc bulging were excluded, because disc bulging is not accepted as herniation but is a degenerative change [4].

The case group included 205 patients with LDH on MRI between levels L1 and S1 (apart from intravertebral disc hernia). In the control group there were 187 patients with disc hernia not identified on MRI. The case group included 105 males and 100 females, while the control group included 88 males and 99 females. In the case group 86 patients ( 54 males and 32 females) were under the age of 40 years, while 119 patients (51 males and 68 females) were 40 years of age or older. In the control group, a total of 90 patients ( 45 males and 45 females) were under the age of 40 years, while a total of 97 patients ( 43 males and 54 females) were 40 years of age or older.

\section{Imaging and data analysis}

Images were obtained with a 1.5 T MR device (Signa Excite; General Electric Medical systems, Milwaukee, WI, USA) with patients lying on the MR table in a supine position. Sequences investigated were T2 fast spin-echo (FSE) (time to repetition [TR]/time to echo [TE] $3300 \mathrm{~ms} /$ $91 \mathrm{~ms}$ ), and scans were $4 \mathrm{~mm}$ slice thickness parallel to discs from $L 1$ to $S 1$ vertebrae in the axial plane. In the sagittal plane, $4 \mathrm{~mm}$ thickness slices with T1 FSE (TR/ TE $440 \mathrm{~ms} / 15 \mathrm{~ms}$ ) and T2 FSE (TR/TE $3600 \mathrm{~ms} / 105 \mathrm{~ms}$ ) images were obtained.

Magnetic resonance images were evaluated with PACS (picture archiving and communication system) on the hospital automation system. The presence of LDH from L1-S1 levels was separately assessed for each disc level, especially on T2-weighted axial and sagittal images. Hernia types were evaluated as protrusion, extrusion, or sequestration within different locations such as median-paramedianforaminal-extraforaminal from vertebral corpus posterior margin, as in MSUC classification [6]. Degeneration of paravertebral muscles was separately assessed for erector spinae and multifidus muscle groups at the level where the volume of muscles was the thickest; in other words, at L1-2 for erector spinae and at L4-5 and L5-S1 levels for multifidus muscles, not just at the level of $\mathrm{LDH}$.

Fatty degeneration of paravertebral muscles was assessed with a four-point visual scale as used by Kader et al. [7]. On the four-point scale, based on the amount of fat deposition within and around muscles, stage A was normal muscle tissue without fat deposition, stage B was mild fatty striations in muscle, stage $C$ was moderate, and stage D was advanced fat deposition. In stage B there is $<10 \%$ fatty component. In stage $\mathrm{C}$ fat deposition is more prominent but lower than $50 \%$, and in the last stage, $\mathrm{D}$, fatty tissue is more than muscle component, at $>50 \%$ (Figure 2). If there is asymmetrical fatty degeneration in one level, we made the staging according to the side with more fat.

\section{Statistical analysis}

Analysis of data was evaluated with SPSS (statistical package for the social sciences) version 19.0 for Windows operating systems. Normal distribution of variables was investigated with the Kolmogorov-Smirnov test. Descriptive data are presented as mean, standard deviation, frequency, and percentage values. The Mann-Whitney 

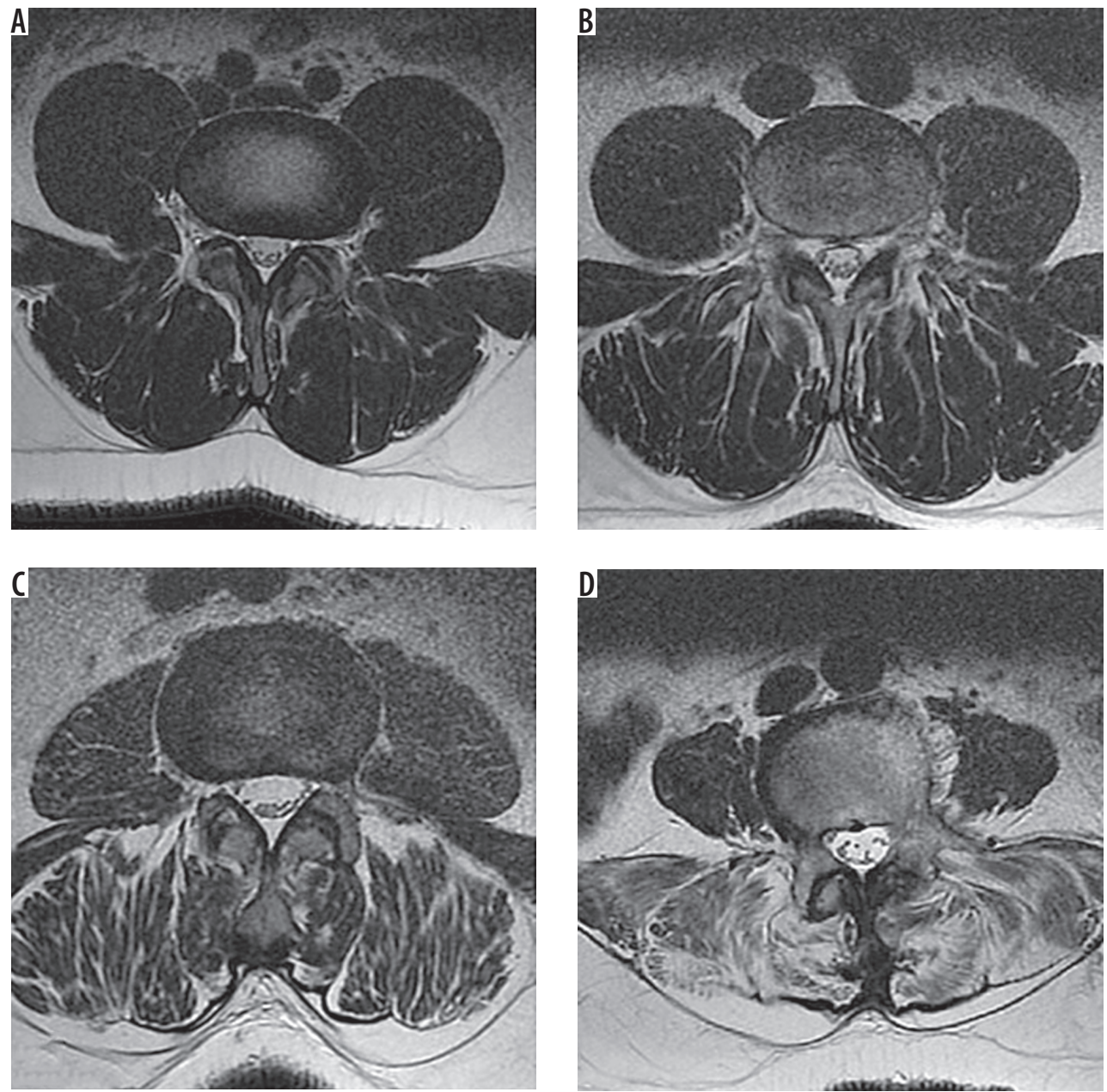

Figure 2. Axial plane T2-weighted magnetic resonance image (A) muscle tissue with no fat, (B) muscle tissue with mild fat, (C) muscle tissue with moderate fat, and (D) muscle tissue with advanced fat deposition

$U$ test was used for comparison of variables without normal distribution between the groups. The $\chi^{2}$ test was used for comparison of dependent and independent groups. Correlation between two measurements was investigated with Kendall's correlation test. $P$ values below 0.05 were accepted as statistically significant.

\section{Results}

Lumbar MRI of 205 individuals (100 females, 105 males) in the case group and 187 (99 females, 88 males) in the control group were examined. The mean ages in case and control groups were $42 \pm 12.4$ and $41.3 \pm 12.4$ years, respectively. When case and control groups are assessed in terms of age and gender distribution, there were no statistically significant differences identified between them ( $p=0.465$ and $p=0.411$, respectively) (Table 1 ).

In the case group, 43 patients were identified as having herniation at more than one level and 5 patients had herniation at 3 levels simultaneously. Among male patients, 15 had upper lumbar level (first three lumbar discs) herniation identified, with eight of these having hernia at more than one level. Among females, 15 patients had up- per level (first three lumbar discs) hernia identified, with five of these having more than one herniation.

Distribution of hernia level according to patient age was 85 patients $<40$ years had lower lumbar level (last two levels) hernias, while two patients had both upper and lower level hernias in the case group. In the group of patients $>40$ years, 17 patients had upper, 90 patients had lower level, and 11 patients had hernia at both levels.

Table 1. Demographic data and lumbar disc herniation in the study groups

\begin{tabular}{|c|c|c|c|}
\hline Parameter & Case $(n=205)$ & Control $(n=187)$ & $p$ \\
\hline Age (mean $\pm S D)$ & $42.0 \pm 12.4$ & $41.3 \pm 12.4$ & $0.465^{a}$ \\
\hline \multicolumn{4}{|l|}{ Sex } \\
\hline Female & $100(48.8)$ & $99(52.9)$ & \multirow[t]{2}{*}{$0.411^{*}$} \\
\hline Male & 105 (51.2) & 88 (47.1) & \\
\hline \multicolumn{4}{|l|}{ Hernia } \\
\hline Superior level & $17(8.3)$ & - & \multirow[t]{2}{*}{$<0.001^{a}$} \\
\hline Lower level & $175(85.4)$ & - & \\
\hline
\end{tabular}

${ }^{*} \chi^{2}$ test, ${ }^{a}$ Mann-Whitney $U$ test. 
Table 2. Degree of fatty degeneration of the muscles in the study group

\begin{tabular}{|c|c|c|c|c|c|c|c|c|c|c|}
\hline \multirow[t]{2}{*}{ Parameter } & \multicolumn{5}{|c|}{ Multifidus, $n(\%)$} & \multicolumn{5}{|c|}{ Erector spinae, $n(\%)$} \\
\hline & Normal & Mild & Moderate & Severe & $p^{*}$ & Normal & Mild & Moderate & Severe & $p^{*}$ \\
\hline \multicolumn{11}{|l|}{ Case } \\
\hline Female & $5(5)$ & $43(43)$ & $50(50)$ & $2(2)$ & \multirow[t]{2}{*}{$<0.001$} & $3(3)$ & $26(26)$ & $70(70)$ & $1(1)$ & \multirow[t]{2}{*}{$<0.001$} \\
\hline Male & $24(22.8)$ & $52(49.5)$ & $28(26.7)$ & $1(1)$ & & $24(22.9)$ & $37(42.5)$ & $50(47.6)$ & 0 & \\
\hline \multicolumn{11}{|l|}{ Control } \\
\hline Female & $15(15.2)$ & $31(31.3)$ & $51(51.5)$ & $2(2)$ & \multirow[t]{2}{*}{$<0.05$} & 18 (18.2) & $23(23.2)$ & $56(56.6)$ & $2(2.2)$ & \multirow[t]{2}{*}{$<0.05$} \\
\hline Male & $16(18.2)$ & $43(48.9)$ & $29(33)$ & 0 & & $18(20.5)$ & $37(42)$ & $33(37.5)$ & 0 & \\
\hline \multicolumn{11}{|l|}{ Case } \\
\hline Age $<40$ years & $23(26.4)$ & $49(56.3)$ & $15(17.2)$ & 0 & \multirow[t]{2}{*}{$<0.001$} & $23(26.4)$ & $37(42.5)$ & $27(31)$ & 0 & \multirow[t]{2}{*}{$<0.001$} \\
\hline Age $\geq 40$ years & $6(5.1)$ & $46(39)$ & $63(53.4)$ & $3(2.5)$ & & $4(3.4)$ & $20(16.9)$ & $93(78.8)$ & $1(0.8)$ & \\
\hline \multicolumn{11}{|l|}{ Control } \\
\hline Age $<40$ years & $26(29.2)$ & $44(49.4)$ & $19(21.3)$ & 0 & \multirow[t]{2}{*}{$<0.001$} & $32(36.0)$ & $33(37.1)$ & $24(27.0)$ & 0 & \multirow[t]{2}{*}{$<0.001$} \\
\hline Age $\geq 40$ years & $5(5.1)$ & $30(30.6)$ & $61(62.2)$ & $2(2)$ & & $4(4.1)$ & $27(27.6)$ & $65(66.3)$ & $2(2)$ & \\
\hline \multicolumn{11}{|l|}{ Hernia level } \\
\hline $\mathrm{L} 1-2, \mathrm{~L} 2-3, \mathrm{~L} 3-4$ & $1(5.9)$ & $5(29.4)$ & $10(58.8)$ & $1(5.9)$ & \multirow[t]{3}{*}{$<0.001$} & $1(5.9)$ & $2(11.8)$ & $14(82.4)$ & 0 & \multirow[t]{3}{*}{$<0.001$} \\
\hline L4-5, L5-S 1 & $27(15.4)$ & $84(48)$ & $64(36.6)$ & 0 & & $26(14.9)$ & $52(29.7)$ & $97(55.4)$ & 0 & \\
\hline All levels & $1(7.7)$ & $6(46.2)$ & $4(30.8)$ & $2(15.4)$ & & 0 & $3(23.1)$ & $9(69.2)$ & $1(7.7)$ & \\
\hline
\end{tabular}

${ }^{*} \chi^{2}$ test.

In male patients of the case group, $24 \mathrm{did}$ not have fat deposition in the erector spinae; however, 37 patients had mild and 50 patients had moderate fat deposition. For the multifidus muscle, 24 patients had no fattening, while 52 patients had mild, 28 patients had moderate, and one patient had advanced fat deposition. For erector spinae muscle in females, three patients had none, while 26 patients had mild, 60 patients had moderate, and one patient had advanced fat deposition. For the multifidus muscle, five patients had none, 43 patients had mild, 50 patients had moderate, and two patients had advanced fat deposition identified (Table 2).

In the control group of male patients, for the erector spinae, 18 had none, 37 had mild, and 33 had moderate degree of fat deposition. For the multifidus, 16 males had none, 43 patients had mild, and 29 patients had moderate fat deposition. For females, in the erector spinae muscle 18 patients had no fat, while 23 patients had mild, 56 patients had moderate, and two patients had advanced fat deposition. For the multifidus muscle, 15 patients had none, while 31 patients had mild, 52 patients had moderate, and two patients had advanced fat deposition (Table 2).

Patients in the case group aged $>40$ years had more fat in both erector spinae and multifidus $(p<0.001$ and $p<0.001$, respectively). Similarly, females in the case group had more fat in the erector spinae and multifidus muscles compared to males $(p<0.001$ and $p<0.001$, respectively). Similar to the case group, in the control group more fat deposition was identified for both erector spinae and multifidus for females ( $p=0.014$ and $p=0.024$, respectively) and in patients $>40$ years of age $(p<0.001$ and $p<0.001$, respectively) (Table 2 ).

When case and control groups are compared (Figures 3 and 4), there were no significant differences between fat deposition in both erector spinae and multifidus muscles ( $p=0.140$ for erector spinae and $p=0.556$ for multifidus) (Table 3). Patients with upper lumbar level hernia were observed to have moderate fat for both multifidus and erector spinae (58.8\% and $82.4 \%$, respectively). However, patients with lower lumbar level hernia had mild and moderate degrees of fat in these muscles ( $48 \%$ and $55.4 \%$, respectively). Patients with hernia at all levels were identified to have mild degree of fat deposition in multifidus and moderate degree in the erector spinae, like patients with lower level hernia (46.2\% and 69.2\%, respectively). The $p$ values for these were identified to be $<0.001$ for both muscle groups (Table 2).

Erector spinae and multifidus fat deposition was correlated in 155 patients in the case group. Of these, 79 were identified to be normal or have mild fat in both muscle groups. For 76 patients, both muscle groups were identified to have moderate-advanced fat. However, 45 patients with normal or mild fat deposition in the multifidus muscle were identified to have moderate-advanced fat deposition in the erector spinae $(p<0.001)$ (Table 4). In the control group, fat deposition in the erector spinae and multifidus were correlated in 176 patients. 

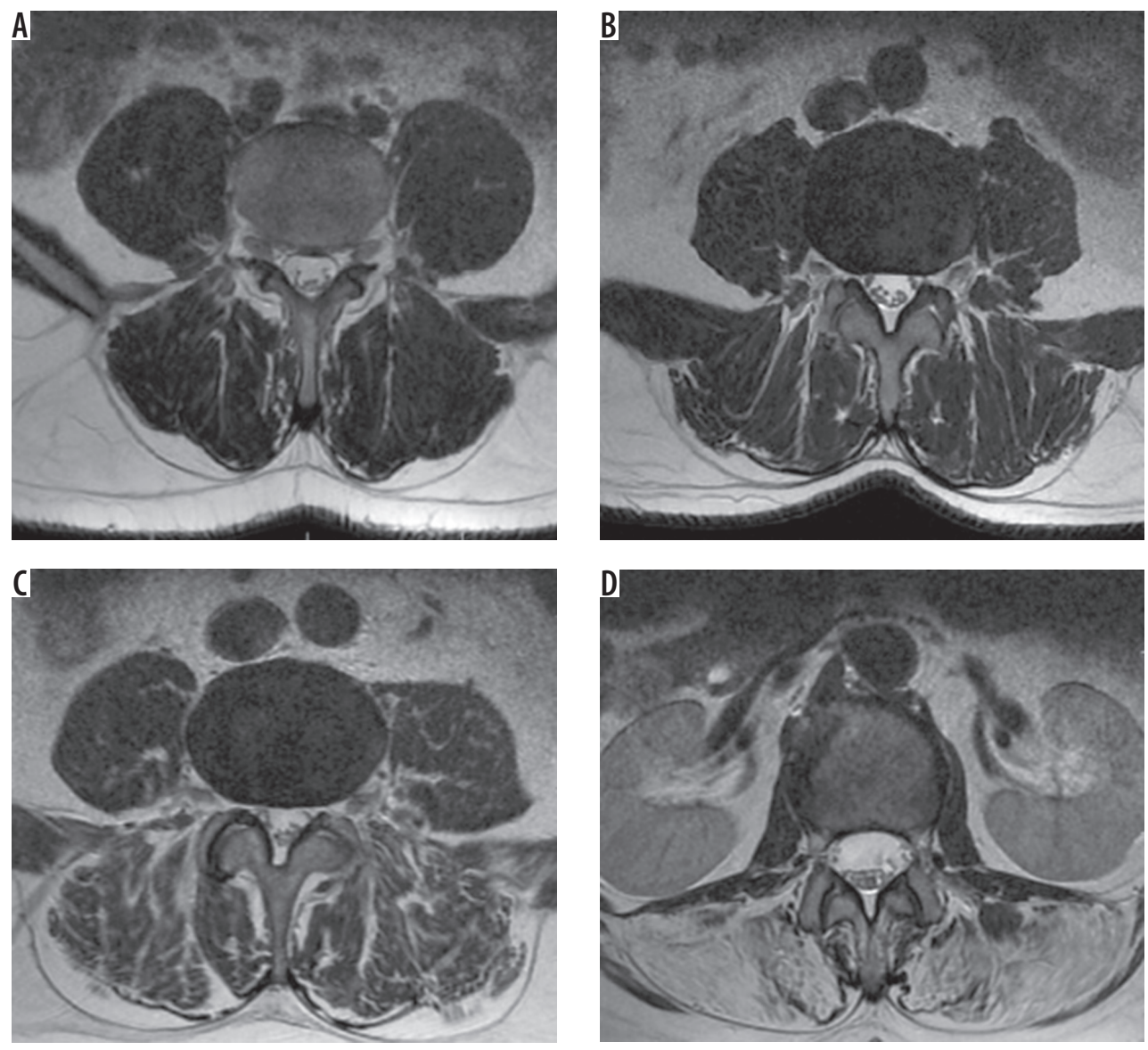

Figure 3. Axial magnetic resonance images showing different degrees of fatty degeneration in the paravertebral muscles of the control group. A) Stage 0 (normal), B) stage 1, C) stage 2, and D) stage 3 fattening

However, 10 patients with moderate-advanced fat deposition in the erector spinae muscle were found to have normal or mild fat deposition in the multifidus muscle $(p<0.001)$.

\section{Discussion}

Most adults have LBP in their lifetime. Among the causes of LBP, a broad framework from traumatic events to working conditions, from demographic characteristics to congenital malformations, are observed. $\mathrm{LDH}$ is a significant cause of LBP and presents at different levels and morphologies.

In the literature, there are many studies comparing fat deposition in the paravertebral muscles - especially the multifidus - with a variety of pathologic situations such as lumbar lordosis flattening [8-12], LBP [13-17], pain spreading to the leg [18], and disc degeneration [16]. However, it is still not fully clear whether fat deposition in the paravertebral muscles is a result or a cause of these pathologies.

Some studies assessed LBP with fatty degeneration of the multifidus or both the multifidus and erector spinae, and some of them support the association of LBP with fatty degeneration [13-15,19-21]. In our study, we also found that muscle fatty degeneration increased with LBP. A variety of studies have used different methods to assess fat deposition. Methods include MRI spectroscopy (MRS) [15], visual scales on MRI [9,14,16,18,20-22], and MRI histogram $[9,19]$, while for assessment of crosssectional area, CT [8,23-25], MRI [8-10,16,20,26-31], and US [26,32] are methods used.

Some studies have shown that fat deposition in paravertebral muscles increases with the aging process $[14,18,22,24]$. In our study, similarly, in both case and control groups patients aged $>40$ years were observed to have more fat deposition compared to patients aged $<40$ years. Another finding that correlated with the literature [22] is that females were identified to have proportionally more fat deposition compared to males.

As correlated with the literature, in our study, $85 \%$ of patients were identified to have hernia at L4-5 and L5-S1 levels, the most mobile segments of the lumbar vertebral column. Additionally, in our study, only $8.3 \%$ of patients had hernia in the first three levels, with all these cases being $>40$ years of age. The remaining patients had hernia identified at both the first three levels and the last two levels.

The degree of fat deposition in erector spinae and multifidus muscle groups in our study was observed to 

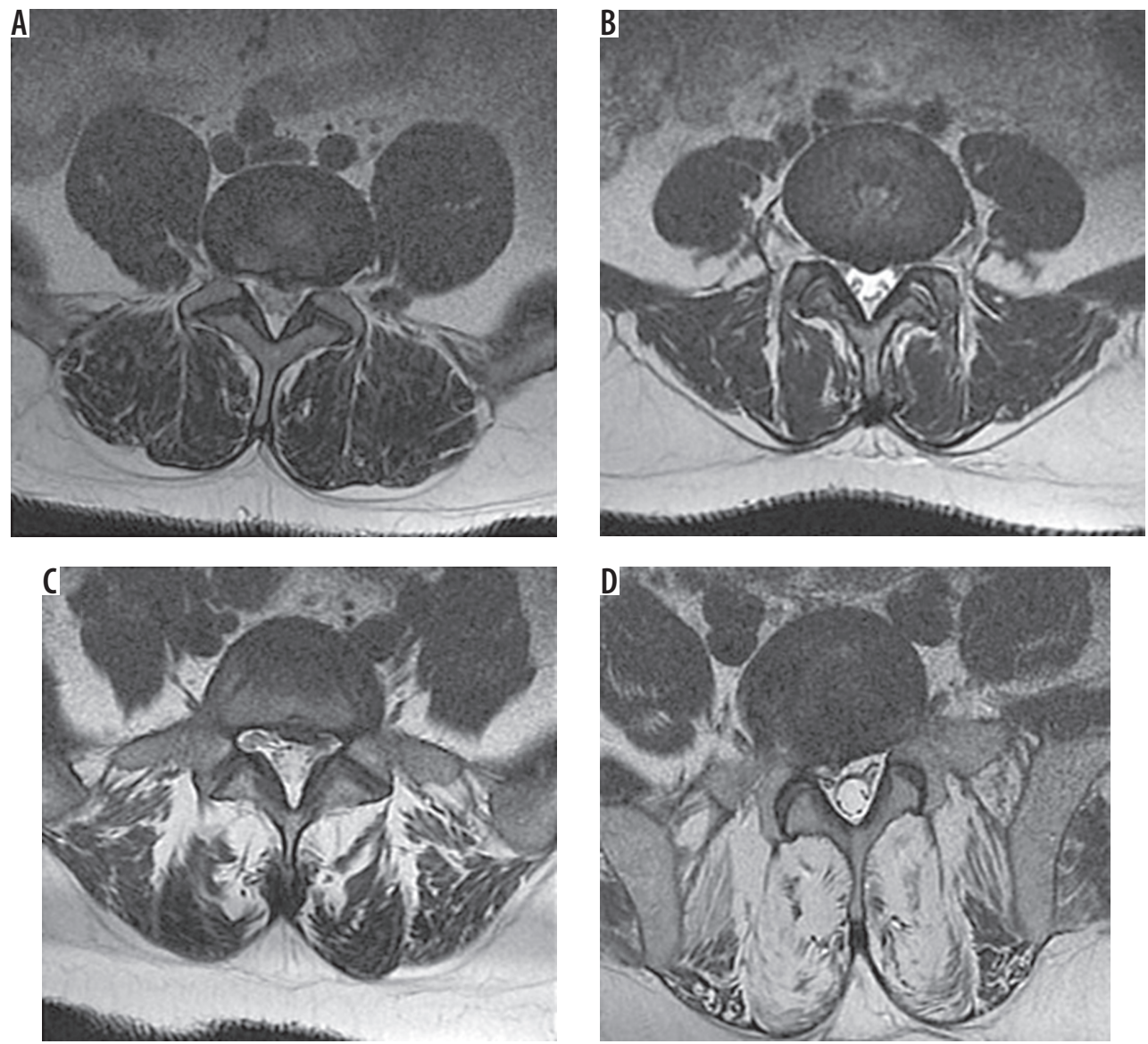

Figure 4. Axial magnetic resonance images show different degrees of fatty degeneration in the paravertebral muscles of the case group. A) stage 0 (normal), B) stage 1, C) stage 2, and D) stage 3 fattening

be similar when case and control groups were compared. This result leads to the consideration that in case and control groups chosen from among patients with LBP, the process causing paravertebral fatty degeneration may not be fully associated with LDH but might be related with LBP.

Table 3. Erector spinae and multifidus muscle fatty degeneration in the study group

\begin{tabular}{|c|c|c|c|}
\hline Parameter & $\begin{array}{c}\text { Case }(n=205) \\
n(\%)\end{array}$ & $\begin{array}{c}\text { Control }(n=187) \\
n(\%)\end{array}$ & $p$ \\
\hline \multicolumn{4}{|c|}{ Erector spinae muscle fatty degeneration } \\
\hline Normal & $27(13.2)$ & $36(19.3)$ & \multirow[t]{4}{*}{$>0.05$} \\
\hline Mild & $57(27.8)$ & $60(32.1)$ & \\
\hline Moderate & $120(58.5)$ & 89 (47.6) & \\
\hline Severe & $1(0.5)$ & $2(1.1)$ & \\
\hline \multicolumn{4}{|c|}{ Multifidus muscle fatty degeneration } \\
\hline Normal & $29(14.1)$ & $31(16.6)$ & \multirow[t]{4}{*}{$>0.05$} \\
\hline Mild & $95(46.3)$ & $74(39.6)$ & \\
\hline Moderate & $78(38)$ & $80(42.8)$ & \\
\hline Severe & $3(1.5)$ & $2(1.1)$ & \\
\hline
\end{tabular}

$p: \chi^{2}$ test
In our study, we compared LDH patients in the first three levels with the last two levels and found correlation between fat deposition in erector spinae and multifidus. There was no clear correlation between degree of fat deposition in muscles with hernia level. Fat deposition in the erector spinae and multifidus was correlated in the control group. Correlation was also identified between a large proportion of fat deposition in muscles in the case group, while 45 patients (22\%) were identified to have more fat in the erector spinae compared to the multifidus. This increase was present for all hernia levels, but it was

Table 4. Fatty degeneration correlation between erector spinae and multifidus muscles in the study group

\begin{tabular}{|l|c|c|c|} 
Erector spinae & \multicolumn{2}{|c|}{ Multifidus lipomatosis degree } & \multirow{2}{*}{$p$} \\
\cline { 2 - 3 } $\begin{array}{l}\text { lipomatosis } \\
\text { degree }\end{array}$ & $\begin{array}{c}\text { Case } \\
\text { Normal-mild } \\
n(\%)\end{array}$ & $\begin{array}{c}\text { Control } \\
\text { Moderate-severen } \\
n(\%)\end{array}$ & \\
\cline { 1 - 3 } Case & $79(94.0)$ & $5(6.0)$ & $<0.001^{* * *}$ \\
\cline { 2 - 3 } & $45(37.2)^{* *}$ & $76(62.8)$ & \\
\hline \multirow{2}{*}{ Control } & $95(99.0)$ & $1(1.0)$ & $<0.001^{* *}$ \\
\cline { 2 - 3 } & $10(11.0)^{* *}$ & $81(89.0)$ & \\
\hline
\end{tabular}

$p: \chi^{2}$ test 
more pronounced for patients with one or more hernia between L1 and L4. The erector spinae muscle plays an important role in balancing the vertebral column. Atrophy of the paravertebral muscles means reducing support of the basic force-countering loads from outside the vertebral column, produced by the erector spinae muscle group [5] and resulting in increased compression of the passive system [6]. Thus, more fatty deposition in the erector spinae muscle compared to the multifidus leads to the consideration that the erector spinae muscle is more affected by the process related to LDH compared to the multifidus, and that this may cause fat deposition rather than be a result of it.

In the literature we did not come across with any study researching the correlation between erector spinae or longissimus muscles in LDH patients with multifidus. Boyac1 et al. [20] assessed two groups of patients with discopathy and non-discopathy LBP in a study and found the fat deposition in the multifidus, paravertebral muscle group (multifidus and erector spinae), quadratus lumborum, and psoas muscles was significantly greater in those with discopathy. However, this study did not separately deal with the erector spinae muscle group. In a study evaluating LBP patients, Ekin et al. [22] identified more hernias at L4-5 and L5-S1 levels in patients with multifidus fatty degeneration compared to patients with none identified. However, this study did not examine erector spinae fat degeneration or whether hernia occurred in patients with and without fat deposition, only that fatty degeneration occurred in hernia patients. Mengiardi et al., in a study assessing fat deposition in the multifidus and longissimus muscles in patients with LBP and those who were asymptomatic [15], found more fat deposition in the multifidus in patients with LBP. However, there was no clear difference identified for the longissimus muscle group. Ploumis et al. [30] compared erector spinae, multifidus, quadratus lumborum, and psoas muscles on symptomatic and asymptomatic sides in patients with disc pathology accompanied by unilateral LBP. They reported that muscles on the symptomatic side had smaller area compared to those on the asymptomatic side. Another similar study by Hyun et al. [31] showed that the multifidus muscle had smaller area on the symptomatic side of patients with unilateral radiculopathy symptoms and accompanying disc hernia. However, this study did not assess the erector spinae.

In the literature there are also studies about patients with LBP and paravertebral muscle fattening being treated with exercise plans. These studies showed that patients with exercise programs for the paravertebral muscles had reduced pain severity and incidence [19,33-36], reduced fat deposition [19], and increased functional capacity $[19,35,36]$. A similar study [37] identified increased muscle strength after an exercise program for patients with chronic LBP. Another study of patients with LDH
[34] reported that exercise treatment caused a reduction in the dimensions of the herniated disc. Considering studies about the importance of exercise and LBP, inclusion of patients in strengthening exercise programs for the multifidus and erector spinae will clearly reduce pressure on the vertebral column and hence trauma. Application of exercises programs for LDH patients will prevent progression of hernia and symptoms and may even ensure amelioration.

There are some limitations in this study. First, we do not know patient BMI values because of the retrospective scanning. However, we think that apart from body fat composition, factors like hypokinesia due to hospitalisation, etc. or psychologic factors like depression could play a role in muscle fat replacement. Also, we do not have enough data about patients' detailed clinical findings, only what was included in records on the hospital automation system, so we could not compare them with our results. Therefore, we have no data about reflection of this fatty degeneration, separate from the muscle groups, in clinical findings. We think further research will be more useful to evaluate the clinical findings comparing fatty degeneration changes in erector spinae and multifidus with prospective studies.

\section{Conclusions}

In our study we investigated fat deposition in erector spinae and multifidus muscles on MR images, in patients with LBP, comprising a case group with LDH and a control group without. The case group was identified to have more fat deposition in the erector spinae compared to the multifidus, and this finding was more pronounced for patients with hernia in levels L1-4. We think it is necessary to support this result of fat deposition observed in the erector spinae group with other studies dealing with exercise programs. The other thing is that for the patient selection, it is known that paravertebral muscle atrophy is more common in women, and its prevalence increases with age, especially after 40 years. It would be better to evaluate the relationship between $\mathrm{LDH}$ and muscle atrophy with patients under the age of 40 years; hence, similar studies with patients younger than 40 years would be better to differentiate muscle atrophy priority.

Another conclusion we reached in our study is that the detailed description of muscle fatty degeneration and grading in radiology reports will benefit planning of physical therapy programs for LDH patients, which will then shorten the rehabilitation process. Additionally, this detail can be used in follow-up exams and MR scans to monitor treatment response.

\section{Conflict of interest}

The authors report no conflict of interest. 


\section{References}

1. Jordan J, Konstantınou K, O’Dowd J. Herniated lumbar disc. BMJ Clin Evid 2009; 2009: 1118

2. Katz JN. Lumbar disc disorders and low-back pain: socioeconomic factors and consequences. J Bone Joint Surg Am 2006; 88 (Suppl 2): 21-24.

3. Rubin DI. Epidemiology and risk factors for spine pain. Neurol Clin 2007; 25: 353-371.

4. Brinjikji W, Luetmer PH, Comstock B, et al. Systematic literature review of imaging features of spinal degeneration in asymptomatic populations. Am J Neuroradiol 2015; 36: 811-816.

5. Barr KP, Griggs M, Cadby T. Lumbar stabilization. Core concepts and current literature, Part 1. Am J Phys Med Rehabil 2005; 84: 473-480.

6. Panjabi MM. Clinical spinal instability and low back pain. J Electromyogr Kinesiol 2003; 13: 371-379.

7. Kader DF, Wardlaw D, Smith FW. Correlation between the MRI changes in the lumbar multifidus muscles and leg pain. Clin Radiol 2000; 55: 145-149.

8. Hyun SJ, Bae CW, Lee SH, Rhim SC. Fatty degeneration of paraspinal muscle in patients with the degenerative lumbar kyphosis: a new evaluation method of quantitative digital analysis using MRI and CT scan. Clin Spine Surg 2016; 29: 441-447.

9. Lee JC, Cha JG, Kim Y, Kim YI, Shin BJ. Quantitative analysis of back muscle degeneration in the patients with the degenerative lumbar flat back using a digital image analysis. Spine 2008; 3 : 318-325.

10. Kang CH, Shin MJ, Kim SM, Lee SH, Lee CS. MRI of paraspinal muscles in lumbar degenerative kyphosis patients and control patients with chronic low back pain. Clin Radiol 2007; 62: 479-486.

11. Pezolato A, De Vasconcelos EE, Defino HL, Noqueira-Barbosa MH. Fat infiltration in the lumbar multifidus and erector spinae muscles in subjects with sway-back posture. Eur Spine J 2012; 21: 2158-2164.

12. Shafaq N, Suzuki A, Matsumura A, et al. Asymmetric degeneration of paravertebral muscles in patients with degenerative lumbar scoliosis. Spine 2012; 37: 1398-1406.

13. Freeman MD, Woodham MA, Woodham AW. The role of the lumbar multifidus in chronic back pain: a review. Am J Phys Med Rehabil 2010; 2: 142-146

14. Hildebrandt M, Fankhauser G, Meichtry A, Luomajoki H. Correlation between lumbar dysfunction and fat infiltration in lumbar multifidus muscles in patients with low back pain. BMC Musculoskelet Disord 2017; 18: 12.

15. Mengiardi B, Schmid MR, Boos N, et al. Fat content of lumbar paraspinal muscles in patients with chronic low back pain and in asymptomatic volunteers: quantification with MR spectroscopy. Radiology 2006; 3: 786-792.

16. Singh R, Yadav SK, Sood S, Yadav RK, Rohilla R. Magnetic resonance imaging of lumbar trunk parameters in chronic low backache patients and healthy population: a comparative study. Eur Spine J 2016; 25: 2864-2872.

17. Hiyama A, Katoh H, Sakai D, et al. The correlation analysis between sagittal alignment and cross-sectional area of paraspinal muscle in patients with lumbar spinal stenosis and degenerative spondylolistthesis. BMC Musculoskelet Disord 2019; 20: 352.
18. Altinkaya N, Cekinmez M. Lumbar multifidus muscle changes in unilateral lumbar disc herniation using magnetic resonance imaging. Skeletal Radiol 2016; 45: 73-77.

19. Woodham M, Woodham A, Skeate JG, Freeman M. Long-term lumbar multifidus muscle atrophy changes documanted with magnetic resonance imaging: a case series. J Radiol Case Rep 2014; 8: 27-34.

20. Boyacı A, Tutoğlu A, Boyacı N, Şen Dokumacı D. Sinir Kökü Kompresyonu Olan Lumbar Diskopatili Hastalarda Paravertebral Kasların Yağ Dejenerasyonlarının MRG ile Değerlendirilmesi. FTR Bil Der 2015; 18: 7-12.

21. Alıcıoğlu B, Demirbağ Kabayel D, Süt N, Emen S. Bel Ağrılarında, Paraspinal Kaslardaki Yağlı Atrofinin TSE-T2 Ağırlıklı MR Sekansı ile Yarıkantitatif Olarak Belirlenmesi. İnönü Üniversitesi Tıp Fakültesi Dergisi 2008; 15: 9-14.

22. Ekin EE, Kurtul Yildız H, Mutlu H. Age and sex-based distribution of lumbar multifidus muscle atrophy and coexistence of disc hernia: an MRI study of 2028 patients. Diagn Interv Radiol 2016; 22: 273-276.

23. Bouche KGW, Vanovermeıre O, Stevens VK, et al. Computed tomographic analysis of the quality of trunk muscles in asymtomatic and symptomatic lumbar discectomy patients. BMC Musculoskelet Disord 2011; 12: 65.

24. Kalichman L, Klindukhov A, Li L, Linov L. Indices of paraspinal muscles degeneration. Clinical Spine Surgery 2016; 29: 465-470.

25. Seungbum C, Jaebum K, Sangbong K. Relationship between low back pain and size and density of the erector spinae muscle and multifidus muscle using CT imaging in a selected community-based population. J Korean Soc Spine Surg 2017; 24: 162-168.

26. Sions JM, Teyhen DS, Hicks GE. Criterion validity of ultrasound 1maging: assessment of multifidi cross-sectional area in older adults with and without chronic low back pain. J Geriatr Phys Ther 2017; 40: 74-79.

27. Lee HI, Lee ST, Kim MY, Ryu JS. Sex differences in predicting chronicity of low-back pain after acute trauma using lumbar muscle area. Am J Phys Med Rehabil 2015; 94: 123-130.

28. Battié MC, Niemelainen R, Gibbons LE, Dhillon S. Is level- and side-specific multifidus asymmetry a marker for lumbar disc pathology? Spine J 2012; 12: 932-939.

29. Barker KL, Shamley DR, Jackson D. Changes in the cross-sectional area of multifidus and psoas in patients with unilateral back pain. The relationship to pain and disability. Spine 2004; 29: E515-E519.

30. Ploumis A, Michailidis N, Chrıstodoulou P, et al. Ipsilateral atrophy of paraspinal and psoas muscle in unilateral back pain patients with monosegmental degenerative disc disease. Br J Radiol 2011; 84: 709-713.

31. Hyun JK, Lee JY, Lee SJ, Jeon JY. Asymmetric atrophy of multifidus muscle in patients with unilateral lumbosacral radiculopathy. Spine 2007; 32: E598-E602.

32. Chan ST, Fung PK, Ng NY, et al. Dynamic changes of elasticity, crosssectional area, and fat infiltration of multifidus at different postures in men with chronic low back pain. Spine 2012; 12: 381-388.

33. Rossignol M, Rozenberg S, Leclerc A. Epidemiology of low back pain: what's new? Joint Bone Spine 2009; 76: 608-613. 
34. Meydan Ocak FD, Karaaslan M, Tutar İ, et al. Lumbar Disk Hernilerinde Konservatif Tedavi Etkinliğinin Klinik Parametreler ve Manyetik Rezonans Görüntüleme Yöntemi ile Değerlendirilmesi. Türk Fiz Tip Rehab Derg 2007; 53: 108-112.

35. Franca FR, Burke TN, Hanada ES, Marques AP. Segmental stabilization and muscular strengthening in chronic low back pain-a comparative study. Clinics 2010; 65: 1013-1017.
36. Sung PS. Multifidi muscles median frequency before and after spinal stabilization exercises. Arch Phys Med Rehab 2003; 84: 13131318.

37. Sipaviciene S, Kliziene I, Pozeriene J, Zaicenkoviene K. Effects of a twelve-week program of lumbar-stabilization exercises on multifidus muscles, 1sokinetic peak torque and pain for women with chronic low back pain. J Pain Relief 2018; 7: 309. 